Case Report

\title{
Mesenteric Inflammatory Venoocclusive Disease in a Patient with Sjögren's Syndrome
}

\author{
Raquel Rios-Fernández, ${ }^{1}$ José-Luis Callejas-Rubio, ${ }^{1}$ Mercedes Caba-Molina, ${ }^{2}$ \\ Rosa Ríos-Peregrina, ${ }^{2}$ and Norberto Ortego-Centeno ${ }^{1}$ \\ ${ }^{1}$ Autoimmune Systemic Diseases Unit, Hospital Clínico San Cecilio, C/Dr. Olóriz s/n, 18012 Granada, Spain \\ ${ }^{2}$ Department of Pathology, Hospital Clínico San Cecilio, C/Dr. Olóriz s/n, 18012 Granada, Spain \\ Correspondence should be addressed to Raquel Rios-Fernández; rriosfer@hotmail.com
}

Received 5 June 2014; Revised 19 September 2014; Accepted 3 October 2014; Published 16 November 2014

Academic Editor: Indraneel Bhattacharyya

Copyright (C) 2014 Raquel Rios-Fernández et al. This is an open access article distributed under the Creative Commons Attribution License, which permits unrestricted use, distribution, and reproduction in any medium, provided the original work is properly cited.

\begin{abstract}
Mesenteric inflammatory venoocclusive disease is an uncommon cause of intestinal ischemia. Certain diseases, such as hypercoagulation disorders, autoimmune diseases, or drugs have been associated with the pathogenesis of mesenteric inflammatory venoocclusive disease. Here, we report a patient with Sjögren's syndrome who underwent surgery for suspected acute appendicitis with a subsequent pathological diagnosis of mesenteric inflammatory venoocclusive disease.
\end{abstract}

\section{Introduction}

Mesenteric inflammatory venoocclusive disease (MIVOD) is an uncommon cause of intestinal ischemia affecting the veins of the bowel and mesentery, which causes thrombotic occlusion of these veins. The etiology of MIVOD remains unclear because it is rarely suspected and often underreported.

The occlusion of mesenteric veins and their tributaries can be associated with various conditions, for example, hypercoagulation disorders, Behçet's disease, systemic lupus erythematosus, and eosinophilic granulomatosis with polyangiitis (Churg-Strauss syndrome) [1-5]. Certain drugs have also been implicated as etiological agents, for example, rutoside, reserpine, methyldopa, and amiloride [6]. In a series of cases with mesenteric venous thrombosis, no predisposing cause was determined [7].

Here we report a patient with Sjögren's syndrome (SS) who underwent surgery for suspected acute appendicitis with a subsequent pathological diagnosis of MIVOD. To our knowledge, this is the first case of MIVOD in a patient with SS, illustrating another possible gastrointestinal manifestation of this syndrome.

\section{Case Report}

A 60-year-old woman, smoker (20 cigarettes/day), with a history of SS, biliary cirrhosis, hypertension, hypercholesterolemia, and osteoporosis presented to the emergency department experiencing initial epigastric pain accompanied by progressive pain in the right lower quadrant, nausea, and fever over the last 12 days. At the time the patient was taking budesonide, ursodeoxycholic acid, enalapril, alendronate, and atorvastatin. She had undergone surgery for carpal tunnel syndrome and since then was taking NSAIDs.

On physical examination, she was normotensive and body temperature was $38^{\circ} \mathrm{C}$. She was found to have lower right quadrant tenderness with peritoneal signs. Bowel sounds were normal.

Laboratory tests showed high C-reactive protein levels $(1.80 \mathrm{mg} / \mathrm{dL} ;$ n.v. $<0.05 \mathrm{mg} / \mathrm{dL})$. White blood cell count and liver and pancreatic enzyme values were within normal ranges. The following results were obtained with autoantibody testing: positive anti-nuclear antibody was identified at a titer of 1:320 with a speckled pattern and the anti-Ro/SS$\mathrm{A} \mathrm{Ab}$ value was $717 \mathrm{U} / \mathrm{mL}$ (n.v. $<10 \mathrm{U} / \mathrm{mL}$ ). Other autoantibodies, including anti-La/SS-B Ab, IgM rheumatoid factor, 


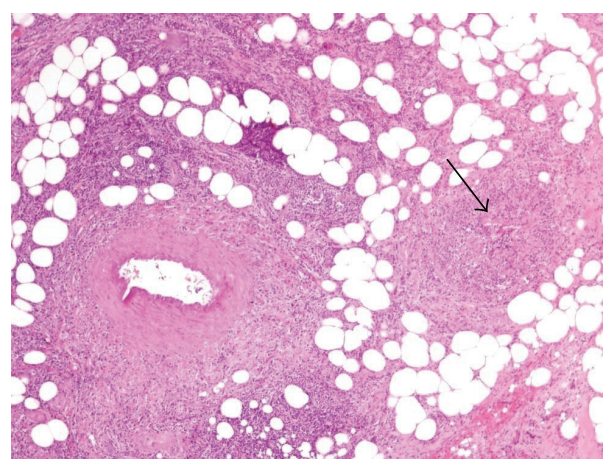

(a)

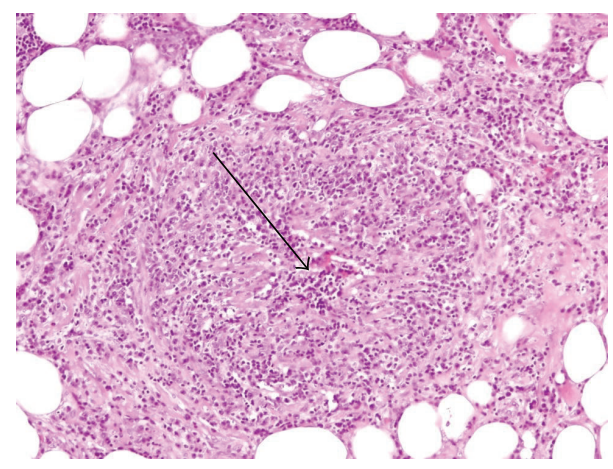

(b)

FIGURE 1: (a) Adipose tissue with heterogeneous intense inflammatory infiltrate consisting of lymphocytes and plasma cells polytypic. The inflammatory infiltrate around the artery but infiltrates vein walls (arrow). $\mathrm{H}$-E original magnification $\times 40$. (b) Higher magnification, a vein totally occluded (arrow). H-E original magnification $\times 100$.

anti-double-stranded DNA, anti-RNP, anti-Scl-70, anti-Jo-1, anti-centromere, IgM aCL, IgG aCL, and lupus anticoagulant, were negative. Coagulation tests were normal.

The abdominal ultrasound showed an ascendant intestinal loop with $14 \mathrm{~mm}$ abnormal wall thickening surrounded by fluid and hepatic steatosis.

The initial clinical impression was that of acute appendicitis and a decision to operate was made. The laparotomy revealed mesenteric congestion of the right colon with widening of the terminal ileum. A normal appendix was removed and a mesocolon biopsy was undertaken.

Microscopic examination revealed marked edema and a perivenular lymphocytic infiltrate with some veins totally occluded. The arteries and arterioles were normal. These histopathological findings are consistent with the diagnosis of MIVOD (Figure 1).

The patient had no postoperative complications and recovered completely; no recurrence was observed during the followup period. Blood tests for hypercoagulability and systemic vasculitis were negative.

\section{Discussion}

Sjögren's syndrome (SS) is an autoimmune exocrinopathy involving mainly the parotid and lacrimal glands, although it can involve almost any other part of the gut. The degree to which SS affects the small and large bowel is unclear. Other symptoms include abdominal discomfort in $0 \%-37 \%$ of the cases, nausea in $0 \%-5 \%$, constipation in $0 \%-23 \%$, diarrhea in $0 \%-9 \%$, and malabsorption in $0 \%-5 \%$. However, documented intestinal involvement is rare to absent in large series [8].

There are few reported cases of SS associated with inflammatory bowel disease, Crohn's disease, or ulcerative colitis $[9,10]$. SS has also been linked with pneumatosis cystoides intestinalis [11], colon cancer [12, 13], protein-losing gastroenteropathy [14], and intestinal pseudoobstruction [15]. Involvement of internal organs is more likely if the vasculitis is associated with cryoglobulins [16].

A distinctive feature of MIVOD is the vasculitis of the mesenteric veins and their intramural tributaries. MIVOD seems to affect the colon in more than $50 \%$ of the patients, although it has also been reported to affect the small bowel, omentum, and gallbladder [17]. It is characterized by mesenteric venous inflammation and thrombosis, which results in chronic ischemia. No involvement of arterial inflammation or occlusion has been described.

Due to discrepancies in histological and imaging findings, these cases constitute a diagnostic challenge.

Inflammatory bowel disease, intestinal ischemia, and acute appendicitis are the major differential diagnosis. It is important to distinguish MIVOD from mesenteric venous thrombosis, as these patients may be put on anticoagulant therapy. Lymphocytic, necrotizing, and granulomatous patterns of inflammation in the mesenteric veins are characteristic features of MIVOD, not found in mesenteric venous thrombosis.

MIVOD is a pathological diagnosis; surgery is required for a definitive diagnosis and decide on the therapeutic procedure. Maintenance therapy is not necessary since the prognosis of MIVOD is excellent. Only one case of recurrent MIVOD has been reported [18]. Our patient recovered completely, and there has been no recurrence in 2 years of followup.

\section{Conflict of Interests}

The authors declare that there is no conflict of interests regarding the publication of this paper.

\section{References}

[1] R. Y. Rhee and P. Gloviczki, "Mesenteric venous thrombosis," Surgical Clinics of North America, vol. 77, no. 2, pp. 327-338, 1997.

[2] R. G. Lee, “The colitis of Behcet's syndrome," The American Journal of Surgical Pathology, vol. 10, no. 12, pp. 888-893, 1986.

[3] S. M. B. Stevens, S. Gue, and E. S. Finckh, "Necrotizing and giant cell granulomatous phlebitis of caecum and ascending colon," Pathology, vol. 8, no. 3, pp. 259-264, 1976.

[4] M. M. Haber, M. Burrell, and A. B. West, "Enterocolic lymphocytic phlebitis: clinical, radiologic, and pathologic features," 
Journal of Clinical Gastroenterology, vol. 17, no. 4, pp. 327-332, 1993.

[5] R. Modigliani, J.-M. Muschart, A. Galian, J.-P. Clauvel, and J.-L. Piel-Desruisseaux, "Allergic granulomatous vasculitis (ChurgStrauss syndrome) - report of a case with widespread digestive involvement," Digestive Diseases and Sciences, vol. 26, no. 3, pp. 264-270, 1981.

[6] E. P. Saraga and J. Costa, "Idiopathic entero-colic lymphocytic phlebitis. A cause of ischemic intestinal necrosis," The American Journal of Surgical Pathology, vol. 13, no. 4, pp. 303-308, 1989.

[7] T. R. S. Harward, D. Green, J. J. Bergan, R. J. Rizzo, and J. S. T. Yao, "Mesenteric venous thrombosis," Journal of Vascular Surgery, vol. 9, no. 2, pp. 328-333, 1989.

[8] E. C. Ebert, "Gastrointestinal and hepatic manifestations of Sjogren syndrome," Journal of Clinical Gastroenterology, vol. 46, no. 1, pp. 25-30, 2012.

[9] R. Gainey, P. J. Rooney, and M. Alspaugh, "Sjogren's syndrome and Crohn's disease," Clinical and Experimental Rheumatology, vol. 3, no. 1, pp. 67-69, 1985.

[10] K. H. Katsanos, V. Saougos, M. Kosmidou et al., "Sjogren's syndrome in a patient with ulcerative colitis and primary sclerosing cholangitis: case report and review of the literature," Journal of Crohn's and Colitis, vol. 3, no. 3, pp. 200-203, 2009.

[11] H. Kato, Y. Nishi, M. Ohyama, T. Tohyama, and M. Nakamura, "A case of pneumatosis cystoides intestinalis developed in a patient with Sjogren syndrome during administration of anetholetrithion," Nihon Shokakibyo Gakkai Zasshi, vol. 102, no. 7, pp. 900-904, 2005.

[12] Y. Nagayama, A. Fujisawa, A. Furutani, T. Otsuki, and H. Yamabe, "Carcinoma of the sigmoid colon associated with Sjogren's syndrome," Journal of Clinical Gastroenterology, vol. 17, no. 3, pp. 268-269, 1993.

[13] M.-Y. Weng, Y.-T. Huang, M.-F. Liu, and T.-H. Lu, "Incidence of cancer in a nationwide population cohort of 7852 patients with primary Sjögren's syndrome in Taiwan," Annals of the Rheumatic Diseases, vol. 71, no. 4, pp. 524-527, 2012.

[14] T.-Y. Hsieh, J.-L. Lan, and D.-Y. Chen, "Primary Sjögren's syndrome with protein-losing gastroenteropathy: report of two cases," Journal of the Formosan Medical Association, vol. 101, no. 7, pp. 519-522, 2002.

[15] Y. Adachi, T. Yabana, T. Kohri et al., "A case of chronic idiopathic intestinal pseudo-obstruction with Sjögren's syndrome," Nihon Shokakibyo Gakkai Zasshi, vol. 87, no. 5, pp. 1223-1227, 1990.

[16] M. Ramos-Casals, R. Solans, J. Rosas et al., "Primary Sjögren syndrome in Spain: clinical and immunologic expression in 1010 patients," Medicine, vol. 87, no. 4, pp. 210-219, 2008.

[17] J. T. Lie, "Mesenteric inflammatory veno-occlusive disease (MIVOD): an emerging and unsuspected cause of digestive tract ischemia," Journal of Vascular Diseases, vol. 26, no. 2, pp. 91-96, 1997.

[18] A. A. Tempia-Caliera, P. Renzulli, K. Z'graggen, T. Lehmann, C. Ruchti, and M. W. Büchler, "Mesenteric inflammatory venoocclusive disease: a rare cause of intestinal ischemia: The first description of recurrent disease," Digestion, vol. 66, no. 4, pp. 262-264, 2002. 


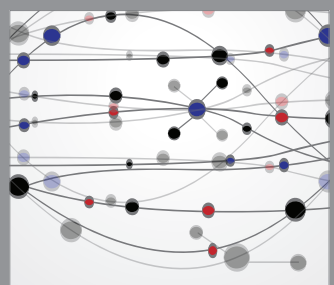

The Scientific World Journal
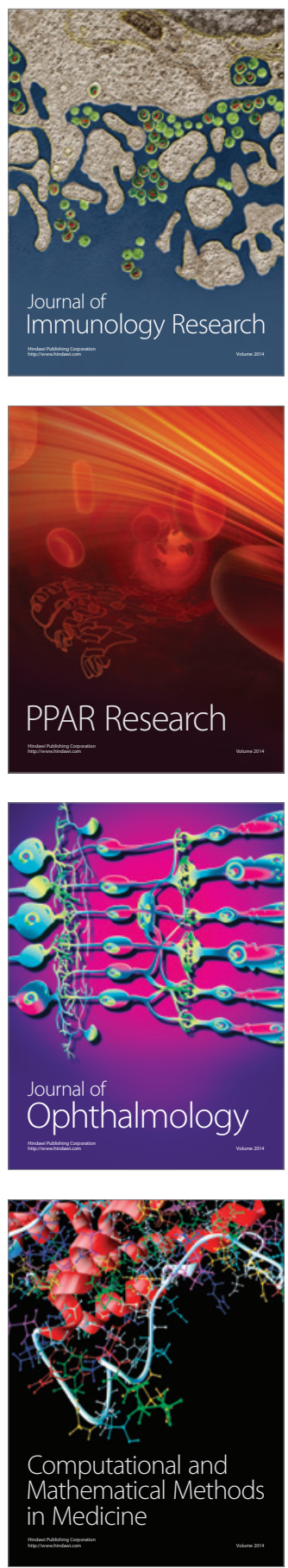

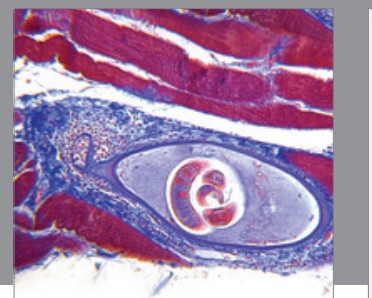

Gastroenterology

Research and Practice
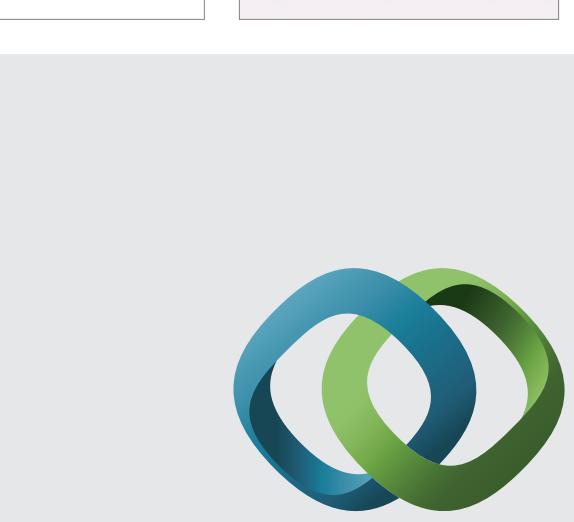

\section{Hindawi}

Submit your manuscripts at

http://www.hindawi.com
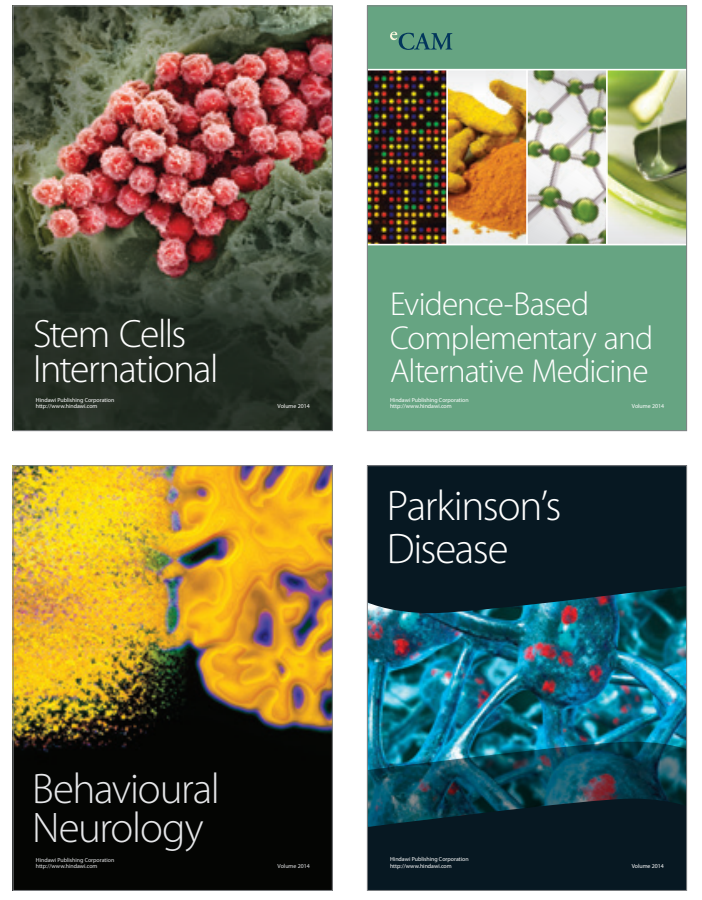
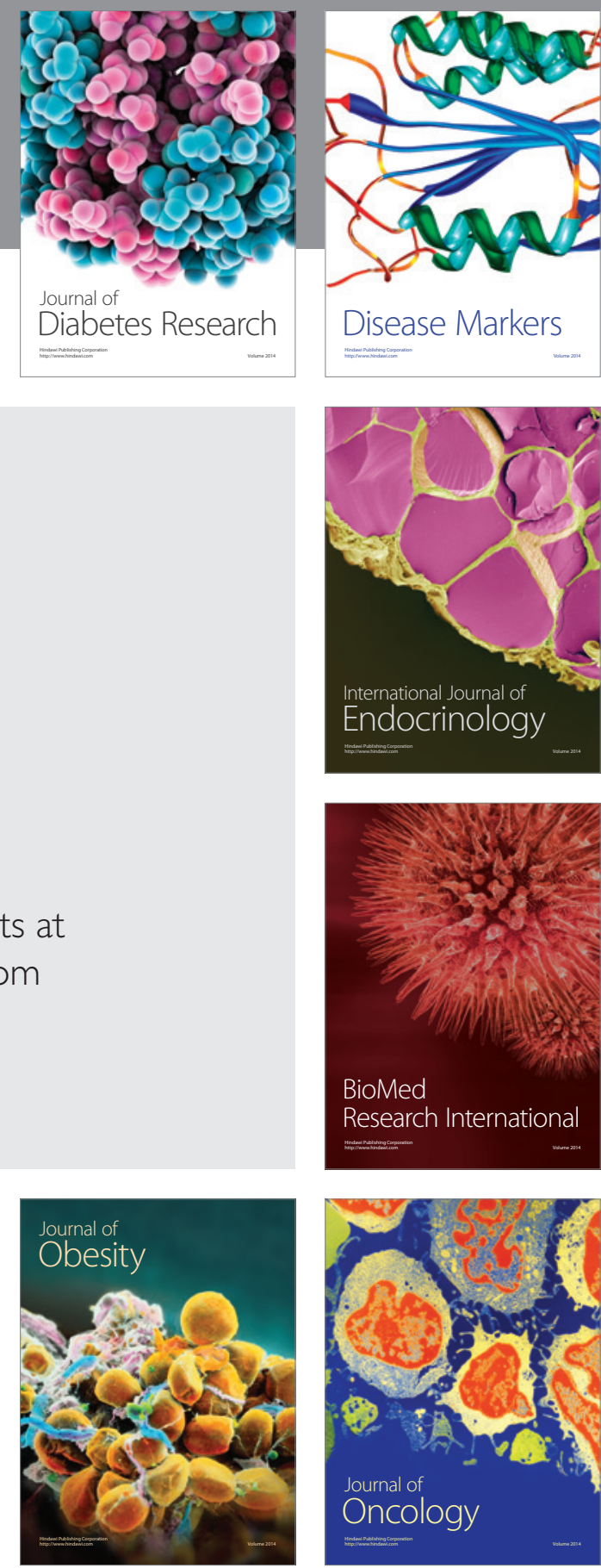

Disease Markers
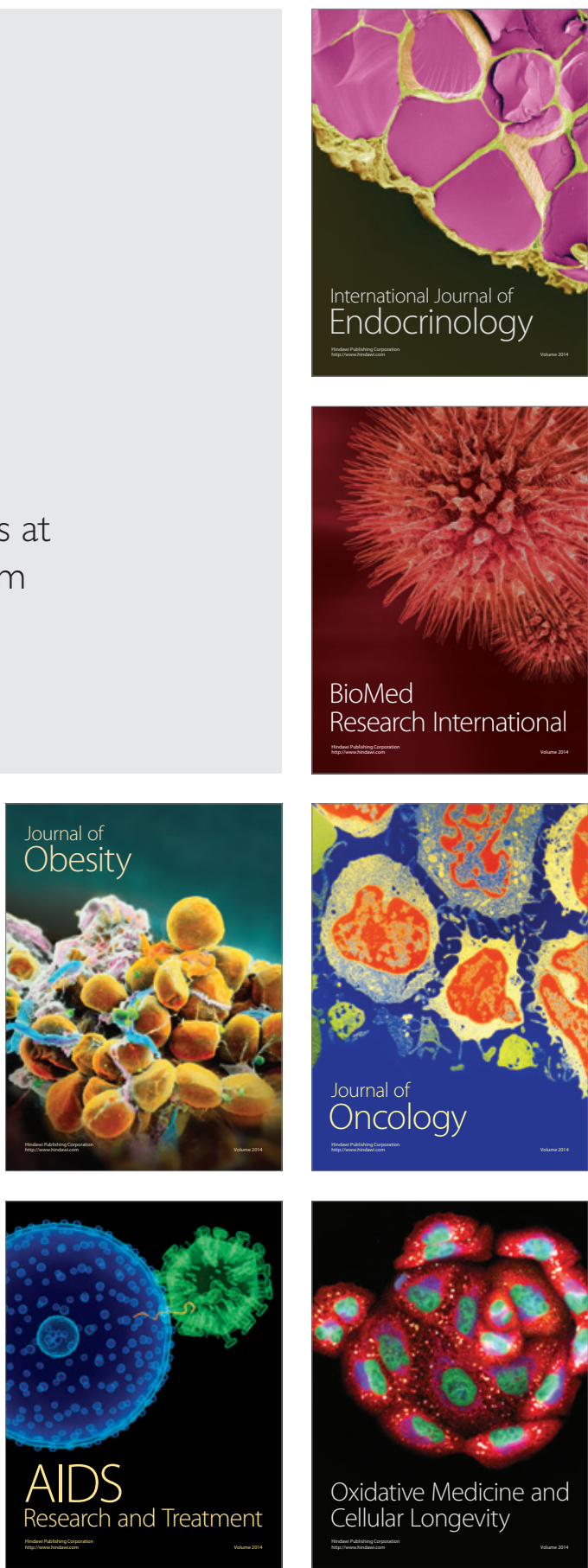